\title{
New Microfilm Reading Machines
}

$\mathrm{F}_{\mathrm{p}}^{\infty}$ OR ALMOST a hundred years it has been scripts photographically at great reductions in size. Yet the extent of the practical usefulness of microphotography to libraries is only beginning to be realized, since the development of reading facilities has not kept pace with that of copying techniques, Many reading machines have been unsatisfactory and the good ones have been expensive. Consequently, libraries have hesitated to purchase microfilm, and when they have overcome their reluctance, the films are too often unread.

But now new reading machines are being made and still others are being discussed. There is hope that the problem of reading microfilm will be solved. There are now four new machines, all table models, all having translucent screens, and none really satisfactory for reading newspapers. To keep the reader abreast of what is going on in this field a brief description and evaluation of these is here presented. Only the $35 \mathrm{~mm}$. models are included, since library microfilm is almost all of that width. Of the older ones still being made there are but two, the Spencer and the Recordak. These need no description though a word about availability is in order.

\section{Recordak Film Reader Model C}

$\begin{array}{ll}\text { Price: } & \$ 440 \\ \text { Availability: } & 4 \text { months }\end{array}$

For Information: Recordak Corporation 350 Madison Ave. New York City Or a local Recordak office

\author{
Spencer Scholar's Microfilm Reader \\ Price: $\$ 50$ \\ $\$ 16.50$ roll film attach- \\ ment \\ Availability: $\quad 90$ days \\ For Information: American Optical Com- \\ pany \\ Scientific Instrument Di- \\ vision \\ Buffalo 15
}

Amic Reader Projector

Magnification: $14 \mathrm{x}$

Lamp: $\quad$ I00 watt

Screen:

Electricity: $\quad \mathrm{AC}-\mathrm{DC}$ only if specified

Price: $\quad \$ 300$

Availability: Immediate delivery from stock

For Information: American Measuring Instruments Corp.

240 W. 40 th St.

New York City

The last-named is a compact machine enclosed in a wooden cabinet with the projector at the right end and the screen on the front panel at the left. On the right end within convenient reach of the reader when in reading position are the switch, focusing knob, and winding control. There is one handle for winding films forward or backward and, for operating during the motion of the film, an electro-magnetic force which pulls back one of the glass flats between which the film passes and thus protects the film from scratching.

The right end of the cabinet is hinged so that it opens to give access to the projector for loading and unloading. The reels are slipped on the spindles and held in position 
by a spring catch on top. The optical system and bulb are also exposed for removing and cleaning flats and condensers and changing the bulb. It is necessary to remove a spring clip to get at these. The life of the bulb is lengthened by the use of a resistor. The spindles for the reels are square at both top and bottom and if standard reels are to be used it is necessary to specify the need for round tops on the spindles.

The screen is plastic, a colloidal solution which eliminates grain. It can be removed for cleaning by the withdrawal of a pin in the case below it.

At one time on the screen $28 \mathrm{~mm}$. of the film can be projected. This covers the width of $35 \mathrm{~mm}$. film perforated on one side. By the use of a scanning device $32 \mathrm{~mm}$. can be read. This device is simply a mirror on a door at the left end of the cabinet which when moved shifts the image on the screen. Thus, newspapers can be projected on the screen, but smaller than their original size, too small for extensive reading.

The machine can readily be used as a projector by opening the door in the left end. The image may then be read on a separate screen, $24^{\prime \prime} \times 36^{\prime \prime}$, made of the same plastic as the smaller one. Projection on an opaque screen is also possible but requires the reversal of the film in the film gate.

The Amic Microfilm Reader-Projector is a convenient small machine which gives a bright sharp image on the screen. It is well-adapted to the reading of books and manuscripts photographed at reductions not greater than $\mathrm{I} 4 \mathrm{x}$. For newspaper reading an outside screen is required and a reader seated at this screen cannot reach the winding handle.

\section{Diebold Flofilm Microfilm Reader}

Magnification: $\quad$ I $\mathrm{x}$

Lamp: 200 watt
Screen:

$14 \times 14$

Electricity:

Price :

$\mathrm{AC}-\mathrm{DC}$ only if specified

Availability: Immediate delivery

For Information: Diebold, Inc.

2 W. $45^{\text {th }}$ St.

New York City 19

Or a local Diebold office

This is an electrically operated machine. The film is wound forward and backward by push buttons, one for each direction. The speed at which it runs is controlled by a rheostat operated by a knob on the front panel. At the slowest speed the film may be advanced one frame at a time with a little practice.

The Diebold nonreflecting coated glass screen is set into the front panel and below it are two toggle switches, one turning on the light, the other the motors. The full width of unperforated $35 \mathrm{~mm}$. film is projected on the screen at the same time. There are no glass pressure plates. The film is kept flat by tension. The back of the film touches a small portion of a curved glass plate which minimizes danger of scratching. There are two of these plates of slightly different thickness, one for reading negative, the other for positive. The change of plates is necessitated by the fact that the focus is fixed and cannot be adjusted to compensate for the change in the position of the film.

The film is easily loaded on spindles on top of the machine, being threaded between rollers at each side of the projection lens. The head rotates to allow for the reading of text in any position on the film. The cover over the lamp and condensers is removable making them readily accessible.

This is primarily a business reading machine. For library reading the motorized drive is neither necessary nor desirable and the I I $x$ magnification limits its use to material reduced by that amount or less. 


\section{Holbrook Combination Reader}

Magnification :

Lamp:

Screen:

Electricity:

Price :

Availability:

For Information:
$25 \mathrm{x}$

200 watt projection lamp

I 4 x 16 translucent

AC-DC

$\$ 275$

Immediate delivery

Holbrook Microfilming

Service, Inc.

Empire State Building

New York City I

This is a combination $16 \mathrm{~mm}$. and $35 \mathrm{~mm}$. microfilm reading machine which projects only half the width of $.35 \mathrm{~mm}$. film at one time on the screen. There is a scanning device by which the edges may be viewed.

The film and lens project from the machine directly in front of the reader. The screen is above in the tilted front panel. The film holding mechanism revolves through $360^{\circ}$, the spindles having springloader ball-bearing retainers to keep the reels in place when inverted. The machine must be at the edge of the table so that the film carrier extends beyond it to allow the mechanism room to rotate. The film advance handle and the scanning mechanism are immediately in front of the reader.

The light switch is on the left end and the lamp is inside the machine at the left. The opening of a door on the left end swings out a shelf on which is the lamp. There is no housing to be removed when the lamp is changed. Ventilation is provided by a chimney extending to the top of the machine. The unit containing the reflection mirror is sealed off to insure against loss of illumination due to the accumulation of dust. The screen is glass coated with plastic on the inside, permitting cleaning of the front surface with a damp cloth.

Instead of pressure plates to hold the film in position for reading, space plates are used. These are slightly wider apart than the thickness of the film. It is, therefore, unnecessary for them to be opened when the film is advanced. The fixed-focus lens has sufficient depth of field to keep the image in focus in this space.

This, too, is primarily adapted to the field of business. It projects the full width of $16 \mathrm{~mm}$. but for $35 \mathrm{~mm}$. reading, scanning is required on every frame. The position of the winding and scanning mechanism is very handy but makes the taking of notes very awkward without a second table to write on.

\section{Orco-Graphic Microfilm Reader}

Magnification:

Lamp:

Screen:

Electricity:

Price:

Availability :

$15 \mathrm{x}$

Automobile headlight lamp

15 $\times 15$ translucent

AC-DC only if specified $\$ 195$ 30 days

For Information: Graphic Microfilm Corporation

I 2 Liberty St.

New York City 6

This is a versatile machine which may be operated with the projection head in several positions, at the left or right or above the screen. This head revolves through $360^{\circ}$ for reading originals taken in all positions on the film. There are two winding handles, one for each spindle. The reels are fastened securely on the spindles to allow them to be inverted safely.

The full width of $35 \mathrm{~mm}$. film perforated on both sides is projected at one time on the screen. The edges of unperforated film may be brought into view by a scanning device. This, however, is not convenient to use. It is held in position by the tightening of a knurled knob which must be loosened and tightened with every shift. A lens covering the full $35 \mathrm{~mm}$. will be furnished on request, but the magnification is thus reduced to $\mathrm{I} 3 \mathrm{x}$.

There are no pressure plates to hold the film in position. Instead, spring tension holds the film taut and four posts all of 
which revolve hold it in the correct plane.

The scanning device on the Orco-Graphic Reader presents such difficulty in use that it would not be practical to read unperforated film on it except where only occasional shifting was involved. Newspapers, then, while they can be read at
I5 $\mathrm{x}$ require too much shifting, but at $13 \mathrm{x}$ they are not large enough for easy reading. Most library microfilm except newspaper is photographed at reductions less than $15 \mathrm{x}$ and even $13 \mathrm{x}$. This machine will project a bright sharp image of unperforated film at I $3 \mathrm{x}$ or perforated at $15 \mathrm{x}$.

\section{New Cooperative Research Project}

A

NNOUNCEMENT is made of a new cooperative research project to prepare annotated lists and guides for: (I) medieval and Renaissance Latin translations from ancient Greek; and (2) medieval and Renaissance Latin commentaries on ancient Greek and Latin authors.

The list of translations will survey Latin translations, produced from antiquity down to A.D. 1600 , of Greek authors who wrote before A.D. 6oo. It will contain such information as the names of translators with short biographical data; date, place, and circumstances under which individual translations were made; incipits and explicits; references to manuscripts and printed editions containing the translations; and to recent scholarly literature on individual translators. This list will therefore provide a guide to the literary and documentary evidence available for an evaluation of the survival, rediscovery, and reception in the Latin West of ancient Greek writings from antiquity through the Middle Ages and the Renaissance to A.D. 1600 .

The list of commentaries will include information similar to that for translations regarding Latin commentaries, made from ancient times through A.D. 1600 , on authors of Greek and Latin antiquity who wrote before A.D. 60o. It will, however, for the present at least, exclude commentaries on Aristotle; on medical, legal, and canonistic works; on the Bible; and on mediaeval Latin authors. The listing of commentaries, which represent a common but comparatively neglected branch of literature, will supplement information contained in catalogs of old libraries and should provide tangible proof for an appraisal of the use or lack of use made of ancient authors through the centuries before A.D. 1600 .

The completed lists of medieval and Renaissance Latin translations and commentaries should have a direct value for scholars in the fields of history, literature, philosophy, and science. They should serve to illustrate and illuminate an important chapter in the development of scholarship from antiquity through the centuries to A.D. I600.

The project has been approved by the Committee on Renaissance Studies of the American Council of Learned Societies; by the American Philological Association; and by the Medieval Academy of America.

The following scholars are members of the editorial board: R. J. Clements, Harvard; M. E. Cosenza, Brooklyn College; J. Hutton, Cornell University; P. Kibre, Hunter College; P. O. Kristeller, Columbia ; D. P. Lockwood, Haverford; M. R. P. McGuire, Catholic University of America; B. Marti, Bryn Mawr; R. V. Merrill, University of Chicago; E. M. Sanford, Sweet Briar; J. J. Savage, Fordham; J. R. Strayer, Princeton; A. Taylor, University of California, Berkeley; S. H. Thomson, University of Colorado; B. L. Ulman, University of North Carolina. Inquiries regarding the project may be directed to any editor in the above list. 